\title{
REGULATORY ASPECTS OF STATUS EPILEPTICUS
}

Authors: S Shorvon ${ }^{1}$ MD, FRCP, E Trinka² MD, MSc, FRCP

\author{
Affiliation: \\ 1UCL Institute of Neurology, London, UK, \\ ${ }^{2}$ Department of Neurology, Paracelsus Medical University, Christian Doppler \\ Medical Centre, Salzburg, Austria
}

Correspondence: s.shorvon@ucl.ac.uk and e.trinka@salk.at

In this article, we consider four aspects of the regulatory standing of status epilepticus and the difficulties these raise in relation to trials and licensing. These formed the basis of a discussion held at the $6^{\text {th }}$ London-Innsbruck Colloquium on Status Epilepticus, held on April 6th 2017.

\section{IS STATUS EPILEPTICUS A CONDITION (A DISEASE ENTITY) IN ITS OWN RIGHT, OR SIMPLY A SEVERE VARIANT OF A SEIZURE?}

A recent indication by the Committee for Orphan Medical Products (COMP) of the European Medicines Agency (EMA) suggested that they would turn down an application for orphan drug status for a new compound designed to be used in the treatment of status epilepticus, on the basis that status epilepticus' is just a severe manifestation or complication of epilepsy and therefore is not a condition in its own right. This raises interesting questions of principle, and has also quite profound practical implications for drug licensing in the field of status epilepticus.

\section{What is a disease entity?}

Defining a disease is not a simple matter and depends a great deal on the perspective taken. The medical perspective is very different from the society perspective and there are geographic, social, cultural, and historical influences on 'what is a disease'. Two examples are osteoporosis, which switched from being an unavoidable part of aging to a pathology in 1964, and also homosexuality which has travelled in the opposite direction, considered to be an endocrine disorder requiring hormonal treatment right up to the middle of the $20^{\text {th }}$ century (1 - Schmidt and Shorvon 2016).

From a medical perspective, the differentiation of disease from a symptom often depends on the former having a defined cause, which results in the latter. In the case of epilepsy, though, establishing a cause is not necessarily an easy matter, and the complexities are discussed elsewhere (2,3 - Shorvon 2011, 2014).

Definition in mental disease (and including epilepsies, as they are manifestations of disturbance of normal brain activity) is a particularly thorny issue. Indeed, some have doubted the very existence of 'mental disease', considering these to be mainly, or at least to an extent, social constructs. 
Much has been written about the crude commercialism of symptoms, and criticisms have been levelled against the pharmaceutical industry for 'medicalising' human behaviour by creating new diseases and then supplying drugs to treat the new disease' (examples are Ritalin $®$ for attention deficit disorder or Viagra ${ }^{\circledR}$ for female sexual dysfunction). There can be no doubt that the effects of having epilepsy can be hugely influenced by the cultural norms of the time and by geographical location; and any satisfactory definition of epilepsy must take this into account. Oswei Temkin (4 - Temkin 1945) was surely correct when he said that epilepsy was 'a tangle of human history and natural history'. These points are discussed further elsewhere (Schmidt and Shorvon 2016).

Sometimes distinctions are drawn between a disease, disorder and condition. It is true that these have different connotations in societal settings but from the medical perspective are surely essentially the same thing.

\section{Current definitions}

A Condition: The EMA defines a 'condition' as: any deviation(s) from the normal structure or function of the body, as manifested by a characteristic set of signs and symptoms (typically a recognised distinct disease or a syndrome). It is worth noting too that Orphanet, which EMA regulation often relies upon in the field of rare diseases, does not provide any definition of a 'condition', but nevertheless does produce a list of rare conditions. Status epilepticus is not mentioned on this list but does list NORSE (New Onset Refractory Status Epilepticus) as a condition. This too seems anomalous, as NORSE is surely only a form of status epilepticus in which no cause has been found. This makes no sense.

Epilepsy: The ILAE definition of epilepsy is as follows: Epilepsy is a disease of the brain defined by any of the following conditions: (1) At least two unprovoked (or reflex) seizures occurring $>24$ h apart; (2) One unprovoked (or reflex) seizure and a probability of further seizures similar to the general recurrence risk (at least 60\%) after two unprovoked seizures, occurring over the next 10 years; (3) Diagnosis of an epilepsy syndrome. This is in our opinion a banal definition and the focus on whether seizures will recur does not, in our view, get close to the essence of epilepsy (for discussion of current and past ILAE definitions see 5 - Shorvon 2015).

An epileptic seizure: Defining an 'epileptic seizure' is easier than defining epilepsy, for a seizure is a neurobiological event for which the mechanisms are at least partially understood (5-See Shorvon 2015).

Status epilepticus: The ILAE approved definition is: A condition in which the mechanisms of seizure termination fail leading to abnormally prolonged and selfperpetuating seizures (at time point t1). It is a condition that can have long-term consequences (after time point $t 2$ ), including neuronal death and neuronal injury (6 - Trinka et al. 2015).

The COMP is responsible for reviewing applications for orphan designation. To qualify for orphan designation, a medicine must meet a number of criteria: 
- it must be intended for the treatment, prevention or diagnosis of a disease that is life-threatening or chronically debilitating;

- the prevalence of the condition in the EU must not be more than 5 in 10,000 or it must be unlikely that marketing of the medicine would generate sufficient returns to justify the investment needed for its development;

- no satisfactory method of diagnosis, prevention or treatment of the condition concerned can be authorised, or, if such a method exists, the medicine must be of significant benefit to those affected by the condition.

[Bold text is as used by the COMP]. Status epilepticus meets all these criteria (of these there is no argument) but the question arises as to whether it is 'a condition'.

\section{Why should status epilepticus not be considered a condition?}

We can say, that there is compelling evidence, to regard status epilepticus as a condition, which deserves emergency treatments on its own right, just as fever, headache, or bladder dysfunction does, irrespective of its underlying cause. The arguments in favour of considering status epilepticus as a "condition" include: 1. A fundamental property of a seizures is its transience, and this is not the case, by definition, in status epilepticus.

2. The clinical features of the epilepsy are quite different. In super-refractory status epilepticus, the patient is lying in coma of the without any of the clinical manifestations of a 'seizure'. (7 -Bauer and Trinka, Epilepsia 2009)

3. The EEG features are quite different often with periodic epileptiform or rhythmic discharges, lacking any of the features of recurrent seizure. $(8,9,10$ Benitzky et al. Epilepsia 2013; Trinka and Leitinger Epilepsy Behav. 2015) 4. Systemic and autonomic changes and complications are quite different from seizures. (10,11 Sutter et al. Crit Care Med. 2018)

5. The physiology is also different. Status epilepticus is characterized by a failure of inhibitory mechanisms, and notably failure of GABAergic control. There is internalization of GABA receptors at synaptic membranes and also increase in the density of glutamatergic receptors and increased expression of excitatory glutamatergic NMDA receptors. There are also changes in ionic environment, protein expression, second messengers etc. (12-15Betjemann and Lowenstein Lancet neurol 2015; Sperk Epilepsia 2007; Rajasekaran et al. Epilepsia 2015; Joshi and Kapur Epilepsia 2018 in press)

6. The pathology is also completely different with excitotoxic damage to the hippocampus, several thalamic nuclei, and areas of cortex - which simply do not occur in epilepsy (15- Meletti et al. Epilepsia 2018 in press)

7. The aetiology differs in range and extent and Status epilepticus develops out of the blue in at least $50 \%$ of cases without any relationship to epilepsy. $(16,17,18$ Tan et al. epilepsy res 2010; Trinka et al. Epilepsia 2012)

8. The accepted classifications of seizures and epilepsies are quite different status epilepticus. The major divisions of status are into convulsive and nonconvulsive forms. (6 - Trinka et al. 2015)

9. The treatment of status epilepticus and ordinary epilepsy are completely different, with the former including the administration of IV AEDs, and also anaesthetics and hypothermia, immunological and physical therapies. 
$(19,20,21,22$ ferlisis and sh and sh and ferlisi and Trinka et al. Expert Opin Pharmacother. 2016)

10. The clinical settings are completely different, with refractory and superrefractory status epilepticus being managed in intensive care units or emergency departments. (23 Ferlisi et al. Epilepsy Behav. 2015)

11. The prognosis and outcome of the two conditions are quite different, with status epilepticus having a $20-40 \%$ mortality rate and $30 \%$ rate of neurological deficits and consequences including epilepsy. 19 Ferlisi and Shorvon Brain. 2012)

12. In terms of the way the condition is discussed in academic medical circles in experiments, in books, papers, websites, congresses they are obviously distinct. $(6,24)$ Shorvon and Trinka Epilepsy Behav. 2015; Trinka et al. Curr Opin Neurol. 2016)

The counter argument, that status epilepticus is not a distinct condition, can only really be made in early status epilepticus, and to the fact that status can evolve out of an ordinary epileptic seizure. Particularly, when status epilepticus is defined as a seizure of 5 or so minutes in duration, this blurs the distinction between a seizure and status epilepticus - and it is difficult to argue that at 5 minutes there is any clinical or pathological difference between the two conditions, nor indeed any treatment difference, but the likelihood that this seizure will not stop spontaneously. An analogy here of course may be the difference between angina and myocardial infarction, which are clearly distinct conditions, and in our view to deny to define a condition simply because it evolves from another makes little logical sense. Nevertheless, it may be that it would a first step from the regulatory point of view to define refractory and super-refractory status epilepticus independently of early status epilepticus.

This topic was the subject of a lecture and an open discussion session with the delegates at the 6th London-Innsbruck Colloquium on Status Epilepticus and Acute Seizures on April 6 2017. A paper ballot was conducted at the end of this discussion, on the following two

- Should Status Epilepticus be considered as a disease entity for regulatory purposes? XX\% Voted in favour

- (if answer is no to the above) Should Super Refractory Status Epilepticus be considered as a disease entity for regulatory purposes? XX\% voted in favour

\section{CONSIDERATIONS IN STUDIES OF TREATMENT OF STATUS EPILEPTICUS}

There are a number of issues, which require to be considered when designing, or conducting trials of treatment in status epilepticus:

1. The function of treatment:

In general terms, none of the antiepileptic drugs (AEDs) used in status epilepticus are designed to treat the cause, nor do they modify the course or prevent epilepsy developing after status epilepticus, They are symptomatic in its classical meaning. They "only" suppress the seizure generation; hence they are 
not antiepileptic therapies sensu stricto (25 Trinka and Brigo 2014). Indeed, there was a move to rename antiepileptic drugs (AED) to antiseizure drugs, because this would better reflect the symptomatic nature of the treatment (26 French et al. 2013).

2. The licence for currently used AEDs in status epilepticus:

The AEDs which are used in status epilepticus are approved for use in epilepsy on the basis that they prevent the occurrence of seizures in patients with chronic or newly onset epilepsy. In status epilepticus, a drug is needed to interrupt seizures, and this is a quite different situation and one in which the current design of AED regulatory studies do not allow any conclusions to be reached.

In status epilepticus, IV or other parenteral preparations are widely used, and it should be noted:

- None of the currently available parenteral preparations of antiepileptic drugs, with the notable exception of buccal midazolam and rectal diazepam, which are currently licensed for the treatment of "acute repetitive seizures", have demonstrated efficacy in status epilepticus in any well-designed clinical trials. - The labels for phenobarbital and phenytoin has been granted by via so-called "grandmother clauses", and no trials to modern standards were carried out. - The license for the intravenous formulation of newer drugs is for their "use in patients, who are temporarily unable to swallow". For this purpose, bioequivalence studies are all that is required, and have been carried out (eg for drugs such as levetiracetam, lacosamide, carbamazepine, and brivaracetam) usually in only small numbers of healthy adults. (Table 1) - Other drugs used in status epilepticus, such as propofol, thiopental/pentobarbital, or ketamine are licensed for anaesthetic purposes, but not for status epilepticus.

\section{Off-label use:}

Most prescribing in status epilepticus is 'off-label'. In a recent survey from Austria, Germany and Switzerland on 1049 patients with status epilepticus, 42\% received off label therapies as the first line medication: 15\% intravenous levetiracetam and 32\% intravenous midazolam, either alone or in combinations with other antiepileptic drugs (27 Kellinghaus et al. 2017). From a global audit on refractory and super-refractory status epilepticus we are informed, that only a minority is treated within the label (23 Ferlisi et al. 2015). In addition, current clinical treatment guidelines recommend off-label therapies as the first line treatment (e.g. 28-29 Shorvon et al. 2008; Brophy et al. 2012, Fung et al. ,2016).

The fact that 'off label' treatment in status epilepticus is the rule and not the exception, is unsatisfactory for doctors for medicolegal reasons, and also for patients when potentially effective therapies are withheld because of the lack of regulatory approval.

4. Treating the cause Some (non-AED) treatment in super-refractory stage of status epilepticus, such as immune therapies, are directed against the pathological cause. The drug 
developmental pathway and the clinical outcome measures for licensing trials of these drugs are very different from those of drugs suppressing seizures.

\section{Informed consent}

Many if not most patients will be unable to give informed consent, and this poses legal and ethical obstacles, which have to be addressed appropriately by measures, such as deferred informed consent.

\section{Comparator drugs:}

There is also the question of the best comparator drug. Placebo controlled trials in the early stares are unethical, since we know to have effective therapies (benzodiazepines) and to test against best medical practice in the later stages introduces a lot of variability into a trial with effects on sample size and the risk of bias. Most of the drugs, which could be used as active comparators in the established or refractory stages are in fact also off label.

7. The lack of attraction of status epilepticus to industry:

Finally, there is the small market argument from industry. Cases of status are rare, and the mortality is high. Many in the pharmaceutical industry feel that investments in trials are uneconomic, and it is for this reason that status epilepticus needs to be recognised as an orphan disease the regulatory requirements for which are relatively facilitatory when compared to the regulations for drugs in commoner disorders.

\section{TRIALS OF TREATMENT IN STATUS EPILEPTICUS}

In the past years several high class randomized controlled trials have been performed by academic groups, such the Rapid Anticonvulsant Medication Prior to Arrival Trial (RAMPART) (30 Silbergleit et al. 2012). Despite its conservative non-inferiority design, it showed, that there was one arm (IM midazolam) better than IV lorazepam (Point estimates of the main outcome were 0.73 [95\% CI 0.690.78] for IM midazolam and 0.63 [0.59-0.68] for IV lorazepam). In the established phase of status epilepticus (ESE) IV AEDs are currently used, based on doctor's experience, but not on trials. The ESE treatment trial (ESETT) is designed to determine the most effective and/or the least effective treatment of ESE comparing IV fosphenytoin, levetiracetam, and valproic acid. The study was first proposed at the $2^{\text {nd }}$ London-Innsbruck Colloquium in 2009 (31 Trinka and Shorvon 2009) then planed as an open randomized, pragmatic study (32 Cock et al. 2011), and finally realized as double-blind RCT (33 Bleck et al. 2013). This multicentre study uses a Bayesian adaptive design. Up to 795 patients will be randomized initially $1: 1: 1$, and response-adaptive randomization will occur after 300 patients have been recruited. The study recruited ahead schedule and first result can be expected by the end of 2018. Of note, academic institutions have sponsored both aforementioned trials, but not the pharma industry. SAGE pharmaceutical did sponsor the only well-designed randomised controlled study in the stage of super-refractory status epilepticus. This was of Brexanolone, an intravenous formulation of the neurosteroid allopregnanolone, but the study failed to demonstrate effectiveness when compared to placebo, and in the opinion of many was a false negative result due to the considerable 
methodological hurdles of performing studies at the stage of super-refractory status epilepticus.

\section{OPPORTUNITIES FOR REGULATORY TRIALS}

Status epilepticus is a condition, where we need more and better informative trials, and recent experience has shown, that it is possible to perform high-class trials to inform clinicians what the best treatment in each treatment stage of status epilepticus, although these studies are difficult (Table 1). There are a number of issues, which deserve further consideration

1. For patients with pre-existing epilepsy one can assume, that a drug, which is efficacious in chronic treatment of bilateral tonic clonic seizures lasting less than 5 minutes (or the respective $t 1$ in other seizure types), is also efficacious when a seizure lasts 6 minutes or more (the 'extrapolation argument'). We suggest that supportive data for licensing in epilepsy patients could come from extrapolation of the phase III licensing trials for chronic treatment, after testing for homogeneity of cause and age of the included population. Additional safety and bioequivalence data would be all that would then be needed to support the decision for approval in this setting.

2. In the early and established stage of status epilepticus, there are several high class randomized controlled trials comparing various benzodiazepines. In our view, it would be reasonable to assume exchangeability of the treatment effect across all included trials (34 ICWG 2009) allowing network meta-analysis with indirect comparisons to be made (35 Brigo et al. 2015). Such comparisons would be contingent on a common comparator (also known as 'adjusted indirect comparison' (36 Song et al. 2003) or 'common reference-based indirect comparison' (33 ICWG 2009) and this represents a useful tool to provide information on relative efficacy of competing interventions where data from direct comparisons are not available (35 Song et al. 2003) (Figure 1). Indirect comparisons are already used by National Institute for Health and Care Excellence in England and the Canadian Agency for Drugs and Technologies in Health. This approach could be applied for alternative formulations of already licensed drugs; additional data on safety/tolerability and bioequivalence would also need to be provided as supportive material. Pharmaco-EEG studies are also helpful to study the speed of rapid brain entry of new investigational drugs (37 Hardmeier et al. 2011).

3. In the established and refractory stages of status, fundamental physiological changes have taken place such as receptor trafficking and excitotoxic pathways activated. Stopping a seizure in this situation may involve different mechanisms or different properties from stopping short epileptic seizures. In superrefractory status epilepticus, EEG surrogate measures can be used as supportive data (38 39 Husain 2011; Husain 2015)

4. In established status epilepticus there are currently only data from small open randomized trials and observational studies available. Such studies are 
notoriously underpowered (40Brigo and Trinka 2017) and often retrospective and of poor quality data (e.g. 41-43 Höfler et al. 2011; Brigo et al. 2017; Trinka et al. 2014). Data from adequately powered open trials (pragmatic trials) could be informative (31 Cock et al. Epilepsia 2011) and there is some good evidence that blinded and unblinded RCTs usually point to the same direction, differing only in the size of the effect (44 Papanikolaou et al. 2006). Safety data could be derived from well-designed observational trials, in which the necessary data quality, and the study design are defined beforehand (45 Berger et al. 2012). The ESETT study is a milestone in trial design and the data will inform clinicians about the best available treatment in established status. The position of the regulators, is unclear, where there is no difference in the treatment arms. As newer IV treatments are already available (such as brivaracetam and lacosamide) an ESETT II could ideally be needed to address their effectiveness, but it is unlikely, that industry will invest in such a study unless there is a clearly defined regulatory pathway for SE.

5. In refractory status epilepticus, where first and second line therapies failed, and the patient is under anaesthesia, the situation is more complicated and clear clinical endpoints are difficult to define. Again, EEG surrogate measure and safety data in critically ill patients could serve as a starting point for a licensing trial with a clinical endpoint.

\section{CONCLUSION}

There is wide consensus in the medical community, that status epilepticus is a distinct condition, and not just a different type of a seizure. The current situation that most of the patients are treated with off label medication is not only unsatisfactory for the doctors, but brings also some risks for the patients. There is a clear need for more high quality trials at different stages of status epilepticus to better inform the clinicians about the appropriate choice of therapies for their patients. Clear regulatory pathways are needed to attract academia, research institutions, and industry to bring new, more effective drugs on the market for this life threatening condition in the future.

\section{REFERENCES}

1 Schmidt D and Shorvon S. The end of epilepsy? A history of the modern era of epilepsy 1860-1010. Oxford: Oxford University Press, 2016

2 Shorvon S. The concept of symptomatic epilepsy and the complexities of assigning cause in epilepsy. Epilepsy Behav. 2014 ;32C:1-8

3 Shorvon S. Historical introduction: The causes of epilepsy in the pre-molecular era (1860-1960). In: Shorvon SD, Andermann F, Guerrini R (eds) The Causes of 
Epilepsy. Common and Uncommon Causes in Adults and Children. Cambridge University Press, Cambridge 2011 pp 1-20

4 Temkin 0. The Falling Sickness: A History of Epilepsy from the Greeks to the Beginnings of Modern Neurology. Baltimore: Johns Hopkins University Press, 1945.

5 Shorvon S. Definition (Terminology) and Classification in Epilepsy: A Historical Survey and Current Formulation, with Special Reference to the ILAE. Chapter 1 In: Treatment of Epilepsy. Eds Shorvon S, Perucca E, Engel J. Oxford: Wiley 2015.

6 Trinka E, Cock H, Hesdorffer D, Rossetti AO, Scheffer IE, Shinnar S, Shorvon S, Lowenstein DH. A definition and classification of status epilepticus--Report of the ILAE Task Force on Classification of Status Epilepticus. Epilepsia. 2015; 56(10):1515-23.

7. Shorvon SD

Status Epilepticus: its Clinical Form and Treatment in Children and Adults

Cambridge University Press, Cambridge, 1994.

8 Bauer G, Trinka E, Kaplan PW. EEG patterns in hypoxic encephalopathies (post-cardiac arrest syndrome): fluctuations, transitions, and reactions. J Clin Neurophysiol. 2013; 30:477-89

9 Beniczky S, Hirsch LJ, Kaplan PW, Pressler R, Bauer G, Aurlien H, Brøgger JC, Trinka E. Unified EEG terminology and criteria for nonconvulsive status epilepticus. Epilepsia. 2013;54 Suppl 6:28-9.

10 Trinka E, Leitinger M. Which EEG patterns in coma are nonconvulsive status epilepticus? Epilepsy Behav. 2015; 49:203-22.

11 Sutter R, Dittrich T, Semmlack S, Rüegg S, Marsch S, Kaplan PW. Acute Systemic

Complications of Convulsive Status Epilepticus-A Systematic Review. Crit Care Med. 2018; 46:138-145.

12 Betjemann JP, Lowenstein DH. Status epilepticus in adults. Lancet Neurol. 2015; 14:615-24.

13 Rajasekaran K, Joshi S, Kozhemyakin M, Todorovic MS, Kowalski S, Balint C, Kapur J. Receptor trafficking hypothesis revisited: plasticity of AMPA receptors during established status epilepticus. Epilepsia. 2013; 54 Suppl 6:14-6.

14 Sperk G. Changes in GABAA receptors in status epilepticus. Epilepsia. 2007;48

Suppl 8:11-3. Erratum in: Epilepsia. 2007; 48:2382.

15 Sperk G, Drexel M, Pirker S. Neuronal plasticity in animal models and the epileptic human hippocampus. Epilepsia. 2009; 50 Suppl 12:29-31. 
16 Tan RY, Neligan A, Shorvon SD. The uncommon causes of status epilepticus: a systematic review. Epilepsy Res. 2010; 91:111-22.

17 Trinka E, Höfler J, Zerbs A. Causes of status epilepticus. Epilepsia. 2012; 53 Suppl 4:127-38.

18 Shorvon S, Tan R. Uncommon causes of status epilepticus. Epilepsia. 2009; 50 Suppl 12:61-3.

19 Ferlisi M, Shorvon S. The outcome of therapies in refractory and super-refractory convulsive status epilepticus and recommendations for therapy. Brain. 2012; 135(Pt 8):2314-28. Erratum in: Brain. 2013; 136(Pt 7):2326. PubMed PMID: 22577217.

20 Trinka E, Höfler J, Leitinger M, Rohracher A, Kalss G, Brigo F. Pharmacologic treatment of status epilepticus. Expert Opin Pharmacother. 2016; 17:513-34.

21 Shorvon S, Ferlisi M. The treatment of super-refractory status epilepticus: a critical review of available therapies and a clinical treatment protocol. Brain. 2011 134:2802-18.

22 Shorvon S, Baulac M, Cross H, Trinka E, Walker M; TaskForce on Status Epilepticus of the ILAE Commission for European Affairs. The drug treatment of status epilepticus in Europe: consensus document from a workshop at the first London Colloquium on Status Epilepticus. Epilepsia. 2008;49(7):1277-85.

23 Ferlisi M, Hocker S, Grade M, Trinka E, Shorvon S; International Steering Committee of the StEp Audit. Preliminary results of the global audit of treatment of refractory status epilepticus. Epilepsy Behav. 2015; 49:318-24.

Erratum in: Epilepsy Behav. 2015; 52(Pt A):132. Zeid, Yasiri [corrected to Yasiry, Zeid].

24 Trinka E, Brigo F, Shorvon S. Recent advances in status epilepticus. Curr Opin Neurol. 2016; 29:189-98.

25 Trinka E, Brigo F. Antiepileptogenesis in humans: disappointing clinical evidence and ways to move forward. Curr Opin Neurol. 2014; 27:227-35.

26 French JA, White HS, Klitgaard H, Holmes GL, Privitera MD, Cole AJ, Quay E, Wiebe S, Schmidt D, Porter RJ, Arzimanoglou A, Trinka E, Perucca E. Development of new treatment approaches for epilepsy: unmet needs and opportunities. Epilepsia. 2013; 54 Suppl 4:3-12.

27 Kellinghaus C, Lang N, Rossetti AO, Rüegg S, Tilz C, Trinka E, Unterberger I, Uzelac Z, Rosenow F. Making SENSE--Sustained Effort Network for treatment of Status Epilepticus as a multicenter prospective registry. BMC Neurol. 2015; 
10;15:230. doi: 10.1186/s12883-015-0486-y.

28 Shorvon S, Baulac M, Cross H, Trinka E, Walker M; TaskForce on Status Epilepticus of the ILAE Commission for European Affairs. The drug treatment of status epilepticus in Europe: consensus document from a workshop at the first London Colloquium on Status Epilepticus. Epilepsia. 2008;49(7):1277-85.

29 Brophy GM, Bell R, Claassen J, Alldredge B, Bleck TP, Glauser T, Laroche SM, Riviello JJ Jr, Shutter L, Sperling MR, Treiman DM, Vespa PM; Neurocritical Care Society Status Epilepticus Guideline Writing Committee. Guidelines for the evaluation and management of status epilepticus. Neurocrit Care. 2012; 17(1):323.

30 Silbergleit R, Lowenstein D, Durkalski V, Conwit R; Neurological Emergency Treatment Trials (NETT) Investigators. RAMPART (Rapid Anticonvulsant Medication Prior to Arrival Trial): a double-blind randomized clinical trial of the efficacy of intramuscular midazolam versus intravenous lorazepam in the prehospital treatment of status epilepticus by paramedics. Epilepsia. 2011 Oct;52 Suppl 8:45-7.

31 Trinka E, Shorvon S. The proceedings of the Innsbruck Colloquium on Status Epilepticus. Epilepsia. 2009;50 Suppl 12:1-2..

32 Cock HR; ESETT Group. Established status epilepticus treatment trial (ESETT).

Epilepsia. 2011;52 Suppl 8:50-2.

33 Bleck T, Cock H, Chamberlain J, Cloyd J, Connor J, Elm J, Fountain N, Jones E, Lowenstein D, Shinnar S, Silbergleit R, Treiman D, Trinka E, Kapur J. The established status epilepticus trial 2013. Epilepsia. 2013; 54 Suppl 6:89-92.

34 ICWG. Report of the Indirect Comparisons Working Group to the Pharmaceutical Benefits Advisory Committee: assessing indirect comparisons. Canberra (ACT): Australian Government Department of Health and Aging; 2009. http://www.pbs.gov.au/industry/useful resources/PBAC_feedback_files/ICWG\%20Report\%20FINAL2.pdf. Accessed 16 Apr 2015

35 Brigo F, Nardone R, Tezzon F, Trinka E. A Common Reference-Based Indirect Comparison Meta-Analysis of Buccal versus Intranasal Midazolam for Early Status Epilepticus. CNS Drugs. 2015; 29(9):741-57.

36 Song F, Altman DG, Glenny AM, Deeks JJ. Validity of indirect comparison for estimating efficacy of competing interventions: empirical evidence from published meta-analyses. BMJ. 2003;326:472-5.

37 Hardmeier M, Zimmermann R, Rüegg S, Pflüger M, Deuster S, Suter K, Donzelli M,Drewe J, Krähenbühl S, Fuhr P, Haschke M. Intranasal midazolam: 
pharmacokinetics and pharmacodynamics assessed by quantitative EEG in healthy volunteers. Clin Pharmacol Ther. 2012;91(5):856-62.

38 Husain AM. Treatment of Recurrent Electrographic Nonconvulsive Seizures (TRENdS) study. Epilepsia. 2013;54 Suppl 6:84-8.

39 Husain AM. Lacosamide in status epilepticus: Update on the TRENdS study. Epilepsy Behav. 2015; 49:337-9.

40 Brigo F, Trinka E. Randomized controlled trials in status epilepticus: Size matters. Epilepsia. 2017; 58(5):915.

41 Brigo F, Bragazzi NL, Igwe SC, Nardone R, Trinka E. Topiramate in the Treatment of Generalized Convulsive Status Epilepticus in Adults: A Systematic Review with Individual Patient Data Analysis. Drugs. 2017; 77(1):67-74.

42 Höfler J, Unterberger I, Dobesberger J, Kuchukhidze G, Walser G, Trinka E. Intravenous lacosamide in status epilepticus and seizure clusters. Epilepsia. 2011; 52(10):e148-52.

43 Trinka E, Höfler J, Zerbs A, Brigo F. Efficacy and safety of intravenous valproate for status epilepticus: a systematic review. CNS Drugs. 2014; 28(7):623-39.

44 Papanikolaou PN, Christidi GD, Ioannidis JP. Comparison of evidence on harms of medical interventions in randomized and nonrandomized studies. CMAJ 2006; 174(5):635-41.

45 Berger ML, Dreyer N, Anderson F, Towse A, Sedrakyan A, Normand SL. Prospective observational studies to assess comparative effectiveness: the ISPOR good research practices task force report. Value Health. 2012; 15(2):217-30. 